\title{
“BRECHA DE LAS NOTICIAS?”. UNA COMPARACIÓN DE LA OFERTA Y EL CONSUMO DE CONTENIDOS EN NACION.COM Y CRHOY.COM
}

\section{A “NEWS GAP”? COMPARING THE OFFER AND CONSUMPTION OF CONTENTS ON NACION.COM AND CRHOY.COM}

\author{
Larissa Tristán Jiménez* \\ Mariana Álvarez Calvo**
}

RESUMEN

En este artículo se analiza la oferta de contenidos y las tendencias de consumo informativo de los lectores y las lectoras de dos medios digitales en Costa Rica: Nacion.com y CRHoy. com durante el mes de mayo del año 2017. Mediante un análisis de contenido, se logró identificar la agenda temática de los medios y su correspondencia con el tipo de noticia que más interesa a la ciudadanía. Los resultados evidencian una relativa similitud entre la oferta y la demanda de noticias sobre asuntos no públicos en ambos medios de comunicación. A partir de lo anterior, se problematiza la noción de "brecha noticiosa" y se sugiere que la falta de interés por los asuntos públicos en Costa Rica es más estructural que episódica.

PALABRAS CLAVE: ANÁLISIS DE CONTENIDO * MEDIOS DE COMUNICACIÓN * FLUJO DE NOTICIAS * INTERNET * ANÁLISIS COMPARATIVO

\section{ABSTRACT}

This article analyzes the news produced by two online media organizations, Nacion.com and CRHoy.com, during May of 2017. Through a content analysis of the news offered and of the most read daily news on these websites, this paper highlights the media agenda and its level of correspondence with consumers/citizens' interests. Results show a relative similarity between the supply and demand of news regarding non-public matters, in both media. Based upon these findings, this paper challenges the notion of "news gap" and suggests that the lack of interest in public affairs in Costa Rica is more structural than episodic.

KEYWORDS: CONTENT ANALYSIS * MASS MEDIA * NEWS FLOW * INTERNET * COMPARATIVE ANALYSIS

Escuela de Ciencias de la Comunicación Colectiva, Universidad de Costa Rica.

larissa.tristan_j@ucr.ac.cr

** Escuela de Ciencias de la Comunicación Colectiva, Universidad de Costa Rica.

mariana.alvarezcalvo@ucr.ac.cr 


\section{INTRODUCCIÓN}

A pesar de las particularidades que los distinguen, los sistemas democráticos contemporáneos evidencian una serie de fenómenos comunes: una crisis de la institucionalidad, el debilitamiento del Estado, la desafección hacia los partidos políticos tradicionales, la beligerancia del populismo o el resurgimiento de discursos nacionalistas. Los resultados de las pasadas elecciones en Estados Unidos (noviembre de 2016), Francia (abril de 2017) y Alemania (setiembre de 2017) reflejan los alcances que dichos fenómenos pueden llegar a tener sobre las decisiones del electorado.

En esta coyuntura de transición y fractura, lo ideal es que los medios de comunicación estimulen el debate y la crítica racional, no solo porque son instituciones de socialización política sino también porque a través de los contenidos que difunden pueden mediar entre el Estado y las necesidades e intereses de la ciudadanía. Sin embargo, la tendencia global suele ser la contraria pues los medios privilegian los sucesos o el "infoentretenimiento" $y$, aunque continúen articulando su agenda temática a partir de noticias de relevancia política y social, muchas veces las elecciones discursivas que se aplican para presentar este tipo de temas acaban banalizándolos.

¿A qué podría deberse esta tendencia en la oferta de contenidos por parte de los medios? Una posible respuesta es que el sistema de medios, al igual que como ocurre con los sistemas democráticos, experimenta transformaciones que pueden fácilmente devenir en momentos de crisis. Por ejemplo, conforme los medios y las plataformas digitales se van consolidando como la primera opción informativa de las personas, el sector de la prensa escrita continúa experimentando una fuerte crisis que lo ha obligado a replantear por completo sus rutinas de producción (Kim, Chen y Gil de Zúñiga, 2013). Asimismo, los medios de comunicación constituyen empresas que, al estar insertos en un modelo económico neoliberal, persiguen obtener ganancias mediante la venta de publicidad y ello, en ocasiones, va en detrimento de la calidad de los contenidos y de la información.
Por su parte, la ciudadanía tampoco parece estar muy ávida de consumir noticias de interés público pues diversos estudios han detectado una brecha entre los contenidos que ofrecen los medios, principalmente sobre asuntos públicos y las preferencias de las personas lectoras quienes se decantan por las noticias sobre asuntos que no son de interés cívico ni político (Boczkowski y Mitchelstein, 2015).

Si la información es precursora de una ciudadanía comunicativa - como indica Habermas (1989) - entonces es posible pensar que estos cambios en las tendencias de producción y consumo de contenidos informativos no pueden desligarse del ejercicio democrático y ello, a su vez, obliga a pensar la relación entre los cambios que experimenta el sistema mediático y los fenómenos por los que atraviesa el sistema democrático. En presencia de ese escenario, el artículo tiene como objetivo situar esas tendencias globales en el contexto nacional costarricense a partir de dos interrogantes específicas: ¿cuáles temas caracterizan la oferta informativa de dos medios digitales, Nacion. com y CRHoy.com? y ¿qué tipos de noticias consumen las personas lectoras de los diarios analizados?

Los resultados ofrecen una mirada sobre las tendencias en la oferta $y$ la demanda de los contenidos durante un periodo electoral previo a las elecciones presidenciales costarricenses que tuvieron lugar en Costa Rica en febrero (primera ronda) y abril (segunda ronda) de 2018. De manera específica, los resultados problematizan la noción de "brecha de las noticias" referida al entorno mediático costarricense. Asimismo, sugieren que la desafección hacia noticias de interés público es una tendencia generalizada de orden estructural y ofrecen un panorama sobre las tendencias de consumo de los lectores y las lectoras de medios digitales en Costa Rica.

\section{PREMISAS TEÓRICAS}

El fenómeno de la brecha noticiosa no puede ser estudiado sin tomar primero en cuenta los procesos de producción y consumo de contenidos mediáticos. En este apartado, se esbozan algunas premisas teóricas que explican 
dichos procesos con el fin de orientar el análisis y la comprensión de los resultados.

\subsection{LA EFICIENCIA DE LOS MEDIOS DE COMUNICACIÓN}

Siles y Boczkowski (2012) analizan la crisis de los periódicos en función de tres procesos: sus orígenes, sus manifestaciones y sus implicaciones en la vida política y social de las democracias modernas. Asimismo, los autores proponen tomar esta coyuntura como una oportunidad para que la industria se piense así misma de forma crítica e idealmente, innovadora.

De acuerdo con los autores, los orígenes de la crisis de los periódicos son de orden económico, tecnológico y social. A nivel económico, la industria ha experimentado las consecuencias de un modelo de producción excesivamente dependiente de la publicidad y la circulación. Se argumenta que el modelo, al estar más enfocado en lucrar que en informar, no le ha permitido a la industria hacer frente a las demandas del capitalismo informacional, como quedó evidenciado tras la crisis financiera mundial de 2008. A nivel tecnológico, Internet sobresale como el factor más determinante en el declive de los periódicos y en los cambios de los patrones de consumo informativo. Mientras que a nivel social, la crisis de los periódicos se enmarca dentro de cambios más amplios relacionados con la pérdida de credibilidad de los medios en general $y$ del periodismo en particular (Siles y Boczkowski, 2012).

Las crisis y sus consecuencias se hacen evidentes en los recortes de personal en las salas de redacción, la disminución en las utilidades y en las caídas de circulación de los diarios o, en el peor de los casos, en el cierre definitivo de ciertos periódicos. Asimismo, la relación existente entre el sistema democrático y el sistema de medios hace suponer que las implicaciones de esta crisis trascienden a la industria de la prensa impresa. En concreto, se considera que la crisis, al haber modificado los valores y las rutinas del periodismo, incide también a nivel político, social y cultural (Siles y Boczkowski, 2012).

La crisis tiene implicaciones más allá de los periódicos porque los medios de comunicación desempeñan un papel importante en la generación de contenidos y en la fijación de una agenda informativa sobre temas de relevancia social. A lo largo de la historia moderna, los medios han cumplido con esa función de forma más o menos constante pero no siempre bajo el mismo grado de "efectividad" (Prior, 2007).

La noción de efectividad tiene que ver con la calidad, facilidad y accesibilidad con la que los medios enfrentan las demandas que reciben del entramado social. En el marco de coyunturas electorales, la efectividad de los medios se torna aún más relevante, pues tiene que ver con su capacidad para dotar al electorado de la información necesaria para ejercer su derecho al voto de forma competente (Ferrín y Fraile, 2014).

Ahora bien, evaluar la efectividad informativa del sistema de medios contemporáneo en función de otros periodos previos no solo sería anacrónico, sino que tampoco podría ofrecer una explicación convincente. En su lugar, lo que procede es tratar de comprender cuáles procesos históricos han llevado a la prensa a su momento actual.

La prensa escrita, en especial los panfletos y la prensa política, fueron decisivos para la consolidación de la esfera pública en el siglo xviII (Habermas, 1989). No obstante, a partir de la segunda mitad del siglo xix, las grandes empresas empezaron a ejercer un mayor control sobre el sistema de medios y es entonces cuando surge la "prensa de masas" (Glassner, 2009; Habermas, 1989; Chalaby, 1998). La corporativización definitiva de los medios se consolida a partir de la década de 1980 dando lugar a un mayor número de contenidos publicitarios y de entretenimiento en detrimento del comentario social, la crítica racional y el debate político (Greer, 2010). Posteriormente, en las primeras décadas del siglo xxi, la Revolución Digital facilitó cambios en las tecnologías de la comunicación que han tenido un efecto profundo en las tendencias de consumo de contenidos. Por ejemplo, los periódicos -indistintamente de su plataforma o medio de difusión- deben ahora competir en el marco de lo que Prior (2007) denomina un "ambiente mediático de alta elección" (high choice media environment), es decir, un entorno en el que las personas están 
expuestas a opciones ilimitadas de contenidos, lo cual hace todavía más difícil capturar la elusiva atención de los lectores y las lectoras.

La confluencia de estos dos factores, la corporativización de los medios y las posibilidades y presiones derivadas de la comunicación digital, han obligado a los periódicos a replantear sus estrategias de producción y difusión de contenidos, lo cual ha favorecido la creación de géneros híbridos en los que se combina la información con el entretenimiento, es decir, el "infoentretenimiento" (Berrocal, Redondo y Campos, 2012; Imbert, 2003). Esta tendencia discursiva se ve reflejada en las llamadas "noticias suaves" (soft news) caracterizadas por el uso de determinados encuadres $y$ contenidos que apelan a la espectacularidad y a la emoción con el objetivo de lograr retener y conmover a las audiencias.

Las investigaciones sobre este tema han demostrado que las soft news cumplen con su cometido, pues las noticias de corte sensacionalista, deportivo $y / o$ de entretenimiento son las que tienden a preferir las audiencias (Moy, Xenos y Hess, 2009; Morris, 2005). Lo anterior sugiere que los medios de comunicación no son los únicos responsables en este proceso, es decir, para poder comprender por qué ciertos contenidos triunfan en Internet mientras que otros pasan desapercibidos no basta con analizar las presiones que el modelo económico ejerce sobre el sistema de medios contemporáneo, también es necesario ampliar el foco de análisis hacia la ciudadanía en tanto audiencia.

\subsection{LAS ELECCIONES DE LAS AUDIENCIAS}

La variación en la efectividad de los medios tiene consecuencias en la dimensión cognitiva y conductual de las audiencias. A nivel cognitivo, la oferta y la calidad de la información repercuten, entre otras cosas, sobre el acervo de conocimiento político, es decir, "el nivel de entendimiento que poseen los ciudadanos sobre el funcionamiento político en el cual se encuentran inmersos" (Brussino, Rabbia y Sorribas, 2008, p.180). Esto, a su vez, incide sobre el comportamiento cívico y electoral, pues se ha demostrado que las personas que tienen un mayor conocimiento político se involucran más en asuntos de su comunidad y presentan niveles más altos de participación durante las campañas electorales (Delli y Keeter, 1996).

En el proceso de adquisición del conocimiento político, los medios de comunicación desempeñan un papel importante pues se ha constatado que existe una relación positiva entre el consumo de noticias sobre política y el conocimiento político, asimismo, se considera que esa relación informa e influye la conducta electoral (Mondak y Anderson, 2004). En consecuencia, intentar comprender por qué las audiencias prefieren ciertos contenidos en lugar de otros es una inquietud tan necesaria como compleja.

Para algunos autores, la reticencia de las audiencias a consumir noticias relacionadas con los asuntos públicos refleja la desafección que experimentan por la política en general, su desconfianza por las instituciones gubernamentales y la crisis de credibilidad que aqueja a los medios (Tsafati y Capella, 2003). Otra tendencia argumenta que esos factores no son nuevos y que invocarlos no explica del todo las motivaciones que llevan a la mayoría de las personas a elegir un contenido de entretenimiento por encima de otro más político (Xiang y Sarvary, 2007). Para otros investigadores en esta misma línea de pensamiento, la explicación no pasa por las personas sino por los medios, en concreto, se argumenta:

el consumo de noticias, el conocimiento de la política y la volatilización electoral han cambiado no tanto porque las personas son diferentes hoy en día, sino porque el entorno mediático es diferente. La gente no necesariamente ha cambiado; simplemente han cambiado el canal. Y lo habrían hecho antes, si hubieran tenido la oportunidad (Prior, 2007, p. 19).

La pregunta por las preferencias de los lectores y las lectoras de los periódicos no es más que la variación de una duda fundante que ha motivado diversos estudios de la comunicación desde mucho antes del surgimiento de Internet: ¿por qué las personas consumen cierto tipo de contenidos?, ¿qué les motiva a hacerlo y 
cómo los interpretan? En el fondo, es una pregunta sobre la recepción, con la diferencia de que en la era digital las audiencias han pasado de cautivas a interactivas.

La combinación de estos factores hace aún más complejo el estudio de las preferencias de los lectores y las lectoras de los periódicos online. Las premisas teóricas del pasado se evaporan en este entorno digital que, en compensación, ofrece la posibilidad de registrar las huellas de consumo que van dejando las personas a través del análisis del big data. En este entorno, el dato habla con una honestidad sin precedentes.

Como se ha mostrado, en la literatura hay un consenso sobre las motivaciones que han llevado a los medios a combinar los asuntos de índole público con otro tipo de temas, mientras que el estudio de las preferencias de los lectores y las lectoras ofrece, por el momento, más preguntas que respuestas. Entre las pocas respuestas con las que se cuenta por el momento, sobresale la que se refiere a la postura teórica que identifica el valor político de las preferencias mediáticas. Desde esta perspectiva, se argumenta que la relación entre el comportamiento político de las personas no puede, ni debe, ser desligado de su consumo mediático e informativo, es decir, el consumo mediático es una cuestión política porque implica una elección entre un mar de opciones que antes de la comunicación digital simplemente no existían.

En el caso específico de los medios digitales, las elecciones que hacen las personas lectoras de noticias online no siempre coinciden con los contenidos que les ofrecen los medios. Precisamente, la noción de "brecha de las noticias" se refiere a la divergencia entre el tipo de noticias que las organizaciones periodísticas ofertan y el tipo de noticias que demandan $y$ consumen las personas lectoras de medios digitales (Boczkowski y Mitchelstein, 2015).

El estudio de la brecha de las noticias ilustra la dimensión política del consumo mediático porque se ha demostrado que la brecha es más notable durante periodos políticos de normalidad en los que las personas están más interesadas en leer noticias sobre temas deportivos, sensacionalistas o de espectáculos, pero que es menor en los períodos de actividad política intensa en los que las personas prestan más atención a los temas políticos (Boczkowski y Mitchelstein, 2015). Las crisis gubernamentales o las elecciones nacionales son ejemplos típicos de periodos políticos de intensidad en los que la brecha tiende a invertirse como consecuencia del aumento en el consumo de noticias sobre política o economía (Althaus, 2003).

$\mathrm{Al}$ igual que como sucede con la crisis de los periódicos, la brecha de las noticias también tiene repercusiones en el sistema democrático. Al respecto, Boczkowski y Mitchelstein (2015) argumentan que la brecha evidencia la dificultad de los medios para fijar una agenda y esto, aunado al desinterés de los consumidores por los temas políticos, lesiona las posibilidades de construir un "discurso compartido" sobre temas de interés público y nacional. La ausencia de un discurso compartido también limita las capacidades de la ciudadanía para articular sus demandas frente al Estado, es decir, para constituirse en esfera pública, en el sentido que propone Habermas (1989).

\section{METODOLOGÍA}

\subsection{PERIODO DE RECOLECCIÓN DE LOS DATOS}

La recolección de los datos se hizo durante todo el mes de mayo del año 2017. Se eligió este periodo porque representa un hito informativo articulado a partir de la tradición y la ruptura. Tradición porque desde 1890 el Directorio de la Asamblea Legislativa se elige el 1 de mayo, ritual que da por inauguradas las labores anuales del Poder Legislativo y del Poder Ejecutivo. Esta disposición, consignada mediante el Artículo 11 del Reglamento de la Asamblea Legislativa, ha sido quebrantada solo en tres ocasiones: 1) en 1917 durante la dictadura de los hermanos Tinoco, 2) en 1949 en el contexto de la Administración de Otilio Ulate Blanco y 3) en el año 1953 durante la primera administración Figueres-Ferrer. La fecha reviste también un significado histórico en el tanto alude al Día Internacional del Trabajador y a la rendición del ejército de William Walker el $1^{\circ}$ de mayo de 1857, hecho que puso fin a la Campaña 
Nacional y que simboliza la consolidación de Costa Rica como una república soberana e independiente.

Por otra parte, también es un momento de ruptura porque, a diferencia de otros años, el $1^{\circ}$ de mayo de 2017, el Poder Ejecutivo no designó a ningún candidato oficial para la presidencia del congreso y porque las negociaciones se complicaron más de lo habitual a raíz de, al menos, tres factores: 1) las condiciones impuestas por el Partido Liberación Nacional (PLN) para comprometer sus votos, 2) las divisiones internas en el Partido Unidad Social Cristiana (pusc) y en el Frente Amplio (FA) que acabaron facilitando alianzas ideológicamente insospechadas y 3) las aspiraciones individuales de algunos diputados que, en lugar de sumar votos, entrabaron aún más el proceso. Como resultado, se generó un clima de incertidumbre y sospecha que se fue aclarando a tan solo 4 días de la elección, cuando Gonzalo Ramírez, del Partido Renovación Costarricense (PRc), empieza a vislumbrarse como el diputado con mayores posibilidades de alcanzar la presidencia del congreso. Asimismo, el carácter anómalo de la elección del directorio legislativo favoreció que el tema estuviese presente en la agenda mediática a lo largo del mes de mayo del 2017, sobre todo en el ámbito de las noticias digitales.

En función de lo anterior, el estudio se centró en el análisis de las noticias digitales porque en Costa Rica el consumo de estas a través de las redes sociales e Internet va en aumento. Ese incremento se ha visto favorecido por el hecho de que el $60,2 \%$ de los hogares costarricenses tienen acceso a Internet, tal y como se indica en la Encuesta de Hogares (2015) del INEc. De manera más específica, en el informe "Hacia la sociedad de la información y el conocimiento en Costa Rica"1, el porcentaje de la ciudadanía costarricense que se informa mediante Internet pasó del 34,9\% en abril de 2013 al 49,1\% en agosto de 2015. De ese porcentaje, el $52 \%$ se decanta por buscar información en las redes sociales mientras que el $49,1 \%$

$1 \quad$ Los datos provienen del décimo informe elaborado por el Programa de la Sociedad de la Información $y$ el Conocimiento (PRosic) de la Universidad de Costa Rica en el año 2016. consulta los sitios de noticias digitales. Estas tendencias informativas corren en dirección contraria al estancamiento que ha experimentado la prensa escrita, ya que poco menos de la mitad de la ciudadanía costarricenses, un $49,1 \%$ para ser exactos, consulta los diarios tradicionales como fuente de información (Informe de PRosic, 2016).

Los cambios en las tendencias de consumo informativo demandan situar el foco de la investigación en los procesos de producción, circulación y consumo de noticias digitales, es decir, en el estudio del flujo de noticias a través de Internet. Por esas razones, los medios elegidos para este estudio fueron los sitios web de Nacion.com y CRHoy.com, pues son los diarios digitales más consultados por la población costarricense (Informe de PRosic, 2016).

Las estimaciones del Grupo Nación (2018) sugieren que los usuarios y usuarias de Nacion.com se caracterizan por estar en el rango etario de entre los 25 y 44 años. En cuanto a la distribución por género, los datos indican que el $45 \%$ de sus lectoras son mujeres $y$ el $55 \%$ restante son hombres. Por su parte, los usuarios y usuarias de CRHoy.com se encuentran en el rango de edad de los 35 a 44 años. De acuerdo con datos obtenidos en abril de 2018 (CRHoy.com, 2018), el 53\% de las visitantes del diario fueron mujeres mientras que el $47 \%$ hombres.

Si bien no existen datos sobre el perfil socioeconómico de las personas visitantes de estos sitios web, sí es posible afirmar que la mayoría tiene acceso a un teléfono celular inteligente, pues tanto para el caso de CRHoy.com o de Nacion.com, los usuarios y las usuarias acceden al contenido mediante celulares, seguido por las computadoras y las tabletas. Por tanto, es posible argumentar que las personas que consultan estos diarios pertenecen a un segmento de la población que está en edad productiva y/o posee algún tipo de ocupación que le permite acceder a los planes de financiamiento que otorgan las empresas de telecomunicaciones en el país.

Para conformar la muestra de análisis fueron revisados los diarios digitales mencionados todos los días a las 15:00 horas y se 
recolectaron las 10-11 noticias más importantes de acuerdo con su posición en la cuadrícula de la página web. Se eligió recolectar las noticias a esa hora porque las mediciones especializadas sugieren que suele haber más tráfico de personas en redes sociales o en páginas de los sitios webs de noticias en la franja comprendida entre las 13:00 y las 16:00, siendo el pico más alto de consumo a las 15:00 horas 2 .

A cada una de las noticias se le asignó un número en función de su posición (1-11). Para el caso de la recolección de las noticias más leídas se consultó la sección que destina cada uno de los diarios para ese tipo de informaciones y se seleccionaron las 10 primeras notas en orden de preferencia. Al finalizar el periodo de recolección, se obtuvo de CRHoy.com un corpus de 340 noticias de oferta y 311 de noticias más leídas. En el caso de Nacion.com se examinaron 320 en la oferta y 311 de las más leídas por la audiencia.

\subsection{ANÁLISIS DE LOS DATOS}

Cada una de las piezas informativas fue codificada a partir de una matriz que no solo operó como instrumento de recolección de los datos sino que también permitió aplicar el análisis de contenido, método que da la posibilidad de hacer inferencias válidas a partir de un texto $y$ referenciarlas al contexto en el cual el mensaje es producido $y$ difundido. Desde esta perspectiva, el texto y el contexto constituyen dos dimensiones diferenciadas pero concomitantes a la hora de articular observaciones sobre los resultados obtenidos tras el análisis (Krippendorff, 2004).

En un sentido más práctico, el análisis de contenido busca identificar sistemáticamente las estructuras cuantificables de un texto, así como, las tendencias semánticas más recurrentes al interior de un corpus de estudio. Esta orientación cuantitativa hace que los resultados del análisis de contenido sean susceptibles de ser evaluados mediante técnicas destinadas a otorgar evidencias de validez y confiabilidad (White y Marsh, 2006). Por esas razones, el

$2 \quad$ Ver https://www.rakacreative.com/blog/socialmedia/best-time-to-tweet-and-post-to-facebookinfographic/ análisis de contenido es idóneo para estudiar productos de la comunicación (i.e. las noticias) en relación con su contexto de consumo y producción (coyuntura preelectoral y prensa escrita costarricense, respectivamente).

A partir de las estructuras cuantificables del texto y de las preguntas que orientan el análisis, se elaboró una matriz de codificación en la que se incluyeron siete variables:

1) La fecha y hora de publicación: como se explicó con anterioridad, las noticias fueron recolectadas a las 15:00 horas, pero como la publicación de las noticias no siempre coincidía con esa hora en particular, se registró el día y la hora de la publicación.

2) Titular: la noticia se define como una macroestructura de relato compuesta, a su vez, por tres estructuras diferenciadas: titular, entradilla o lead y texto de la noticia. Desde un punto de vista analítico, el titular tiene un valor importante porque condensa el contenido esencial de una noticia (Casals-Carro, 2005). Asimismo, se considera que el titular posee también un efecto cognitivo considerable, pues su contenido es lo que con más seguridad recordarán las lectoras $y$ los lectores de las noticias (van Dijk, 1990). Por estas razones, se incluyó el titular como variable fundamental para el análisis de contenido y también para contrastar el grado de correspondencia entre el título y el texto de la noticia. La convergencia o divergencia entre estas estructuras puede dar pautas sobre las rutinas periodísticas utilizadas para la construcción de una noticia, sobre todo en aquellos casos en los que el titular puede no coincidir con el contenido de la noticia con tal de atraer la atención de los lectores y las lectoras.

3) Género: los géneros periodísticos se definen como "estructuras comunicativas" que cumplen una serie de funciones a nivel social: configurar el ejercicio del periodismo, brindar pautas de referencia al destinatario sobre el tipo de mensaje 
que va a consumir y ordenar la realidad en la medida que separan los hechos de las opiniones (Casals-Carro, 2005). Gomis y Giner (2008) distinguen cuatro géneros periodísticos clásicos: la noticia, el reportaje, la crónica y el editorial. En vista de que cada uno de ellos representa una construcción distinta de la realidad y ostenta una función específica a nivel social, el estudio del género da pautas sobre cómo el medio lleva a cabo el tratamiento de la información y refleja los valores periodísti$\cos y$ las rutinas de producción.

4) Formato: en el contexto de la ecología mediática actual, el discurso periodístico informativo ha adoptado nuevas formas $y$ nuevas modalidades narrativas que combinan distintos recursos semióticos con el fin de generar textos multimodales. A través de esta variable se explora hasta qué punto los medios incorporan estos recursos en la construcción de las noticias digitales.

5) Tipo de contenido: esta variable alude al tipo de contenido de la noticia, en concreto, si aborda un asunto de interés público o no. De acuerdo a la clasificación de Boczkowski y Mitchelstein (2015), los artículos sobre política, economía o política internacional se consideran como "asuntos públicos" mientras que aquellos sobre sucesos, ocio, espectáculos y deportes pertenecen al orden de los asuntos no públicos. Esta variable es fundamental para el estudio de la brecha noticiosa pues permite identificar cuál es el tipo de contenidos que el medio privilegia y si este corresponde con las elecciones de los lectores y las lectoras.

6) Tema: los temas del discurso son importantes de analizar porque cumplen una función ideacional, es decir, la de articular la representación del hecho narrado (Fairclough, 1995). Asimismo, el estudio de esta variable permite identificar la agenda temática e informativa que ofrece el medio y su posterior correspondencia con los temas que más prefieren las audiencias.
7) Periodista o fuente: esta variable alude a la persona, agencia o fuente a la que se le atribuye la autoría de la noticia. A través de su estudio es posible identificar las rutinas periodísticas y los valores que privilegia el medio. Por ejemplo, si la cobertura de un tema se le asigna a un periodista en particular, se puede decir que el medio apuesta por la especialización o si por el contrario, una misma persona cubre varios temas por igual, se puede suponer que el medio privilegia la cantidad de notas por encima de su calidad.

El proceso de análisis se llevó a cabo mediante la lectura de cada una de las noticias y su codificación a partir de las siete variables descritas con anterioridad. La información fue registrada en la matriz analítica a partir de la cual se identificaron las tendencias que se describirán en la sección tres. Antes de pasar a los resultados, se considera necesario aclarar que el análisis del contenido siguió una dirección recursiva, deductiva e inductiva, es decir, los temas derivados de las noticias fueron organizados en categorías que estaban bajo constante revisión a partir de la lectura del corpus y de la puesta en común con las personas integrantes del equipo de investigación.

\section{RESULTADOS}

\subsection{TENDENCIAS EN LA OFERTA INFORMATIVA DE CRHOY.COM}

Tras el recuento del contenido que ofrece el medio en cuestión, $55,2 \%$ de las noticias analizadas fueron clasificadas como de "Asuntos No Públicos" mientras que el $44,8 \%$ fueron catalogadas como "Asuntos de Interés Público". Puede concluirse que el medio prefirió claramente la oferta de asuntos no públicos en la agenda informativa de su sitio Web durante el mes de mayo.

El género periodístico que impera en el medio fue la noticia. Los formatos utilizados en los productos periodísticos fueron, en su mayoría, textos cortos de no más de tres párrafos elaborados solo con los recursos 
semióticos de texto e imagen. Esta estructura de la noticia, con pocos caracteres, devela una dinámica de producción de los periodistas ligada a la inmediatez.

La agenda del medio se construye mediante 10 temas recurrentes, a saber: sucesos $(25,1 \%)$, política $(23 \%)$, deportes $(16,5 \%)$, otros $(7,7 \%)$, infraestructura $y$ transporte $(5,9 \%)$, asuntos sociales $(5,3 \%)$, asuntos internacionales $(5 \%)$, economía (4,7\%), ciencia y ambiente $(4,4 \%)$ y entretenimiento $(2,4 \%)$. Como puede verse en el gráfico 1, las noticias más publicadas son las de sucesos seguidas de noticias de política. Esta tendencia sugiere que el medio articula su propuesta informativa a partir de temas que no son de interés público, aunque otorga cierta importancia a temas que sí lo son, como las noticias sobre política.

\section{GRÁFICO 1 \\ AGENDA INFORMATIVA DEL MEDIO CRHOY.COM \\ MAYO, 2017}

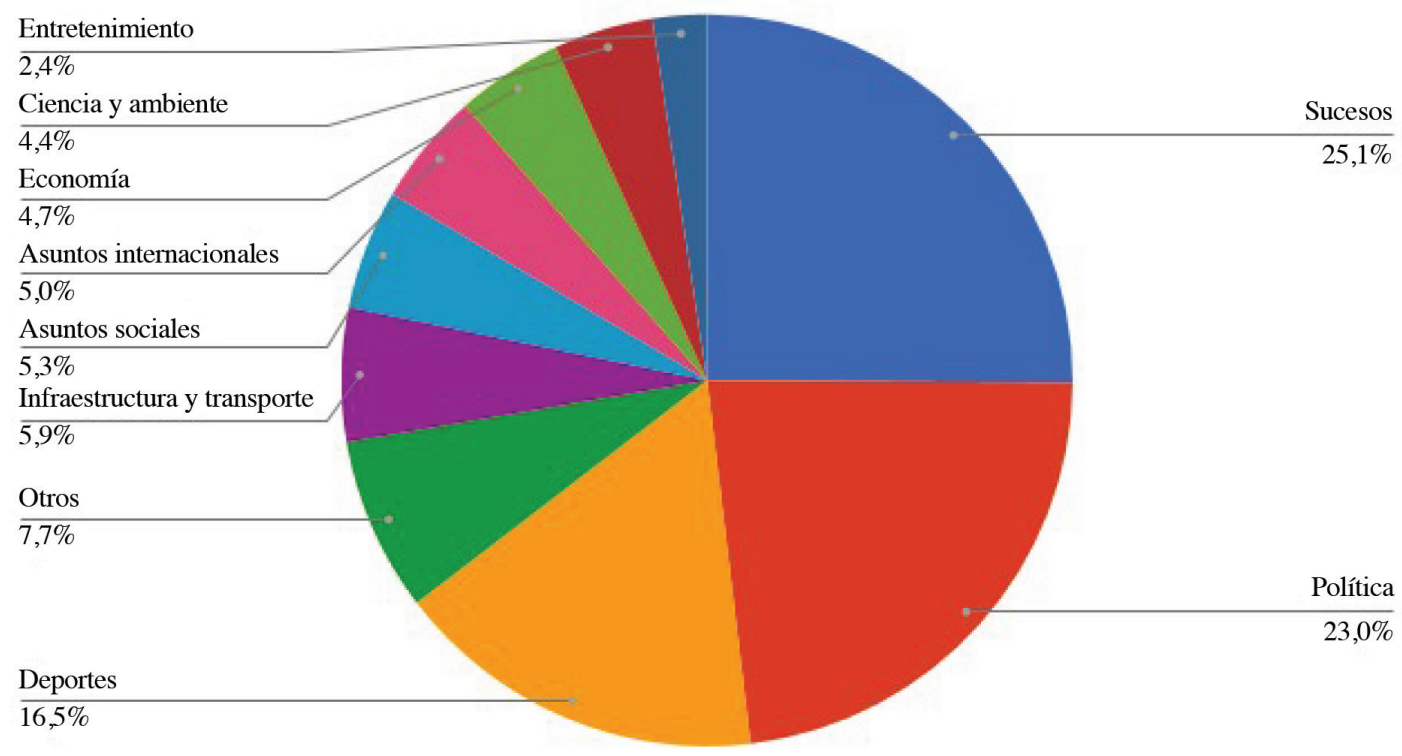

Fuente: Elaboración propia a partir de los datos de CRHoy.com recolectados durante mayo de 2017.

En el marco de la coyuntura particular del 1 de mayo, la noticia más importante según el medio, llevaba como título “Doña Merry', Paquito y la giganta tiñeron de colores la Avenida Segunda" (CRHoy.com, 01/05/2017). El titular - que acompaña una breve nota de 3 párrafos en las que sobresalen muñecos alusivos a los personajes $y$ un video- en realidad no da cuenta del contenido real de la noticia, pues se informaba sobre la tradicional marcha que se lleva a cabo el 1 de mayo en la Avenida Segunda en conmemoración del Día Internacional del
Trabajo. Históricamente, esta marcha ha sido el instrumento que emplean diversos actores sociales (sindicatos, asociaciones sociales, etc.) para posicionarse en defensa de sus derechos o como una forma históricamente legitimada de protesta social. Sin embargo, en la noticia solo se hace una mención tangencial a esa tesitura característica de la marcha del 1 de mayo. Por tanto, se ilustra una tendencia arraigada en el medio: la banalización de un tema de índole público. Por otra parte, en la construcción de la noticia también se ve reflejada una estrategia 
discursiva recurrente de este medio que consiste en elaborar un titular llamativo que logre la atención de la personas lectoras pero que no refleja el contenido de la nota.

Entre las 10 noticias más importantes recolectadas a las 15:00 del día $1^{\circ}$ de mayo, solamente tres hicieron alusión a la elección del directorio de la Asamblea Legislativa, a saber: "Gonzalo Ramírez suma votos y se acerca a presidir el congreso" (Ugarte, CRHoy.com, 01/05/17), "iSin humo blanco! Diputados tomarán cuarto receso" (Ugarte, CRHoy.com, 01/05/17) y "Diputado Juan Marín: Nadie está alcanzando los 29 votos" (Ramírez, CRHoy. com, 01/05/17). Una cuarta noticia, titulada "Mayoría de diputados se apegó al protocolo" (Castro, CRHoy.com, 01/05/17) tiene relación con los acontecimientos del 1 de mayo, pero no desde la óptica del acontecimiento político sino desde la crónica social en la medida que busca identificar a los diputados y las diputadas que siguieron los dictámenes del protocolo o que, por el contrario, lo infringieron.

\subsection{TENDENCIAS EN LA DEMANDA DE CRHOY.COM}

A diferencia de las noticias ofrecidas por el medio en el mes de mayo de 2017, donde existió una ligera preferencia por asuntos no públicos, el $82,9 \%$ de las noticias más leídas fueron de "Asuntos No Públicos", mientras que el 17,1\% fueron noticias sobre "Asuntos Públicos". Utilizando los parámetros de Boczkowski y Mitchelstein (2015), la divergencia entre la oferta y el consumo de asuntos públicos es de $27,7 \%$ en el caso de CRHoy.com. Estos autores encontraron cifras parecidas para medios de comunicación en Europa y América Latina como Folha (Brasil) (25\%), El Mundo (España) (23\%), The Guardian (Reino Unido) (31\%) y The Times (Reino Unido) (24\%). Esta tendencia revela poco interés por los temas de orden público entre una parte de las personas que consultan CRHoy.com.

Tal y como puede observarse en el gráfico 2, los temas más leídos por las personas fueron: sucesos $(31,9 \%)$, entretenimiento $(17,4 \%)$, deportes $(16,5 \%)$, otros $(13,9 \%)$, política $(7,4 \%)$, asuntos internacionales (1,9\%), infraestructura y transportes $(2,9 \%)$, economía $(1,3 \%)$ y por último, ciencia y ambiente $(0,9 \%)$.

\section{GRÁFICO 2 \\ DEMANDA DEL MEDIO CRHOY.COM \\ MAYO, 2017}

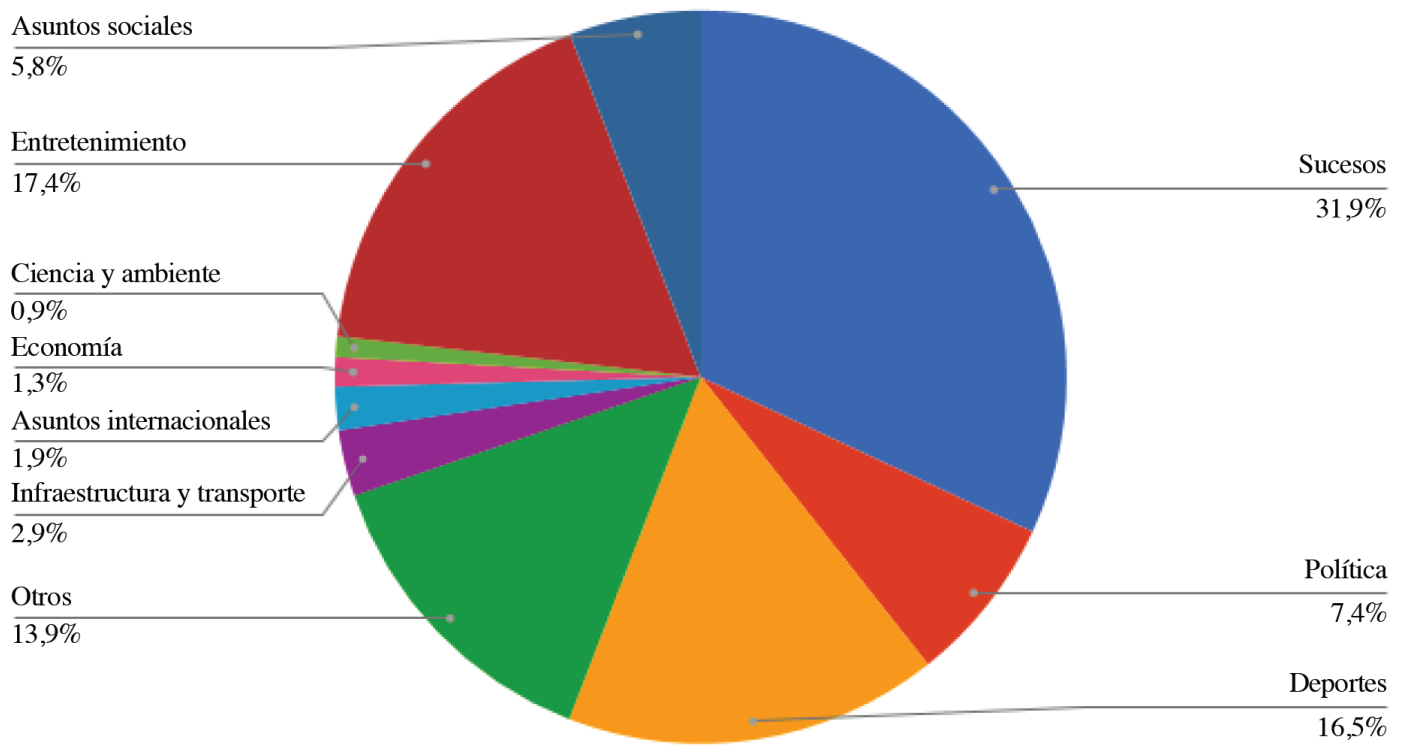

Fuente: Elaboración propia a partir de los datos de CRHoy.com recolectados durante mayo de 2017. 
La noticia más leída a las 15:00 del día $1^{\circ}$ de mayo ilustra las preferencias en el consumo informativo de la audiencia de CRHoy.com. La noticia se tituló "Tico de 8 años deslumbró ayer en televisión" (Otey, CRHoy.com, 01/05/17) y trataba sobre la participación de un niño llamado Andrey Ramírez en un programa de concursos de la televisión estadounidense. El tema legislativo no estuvo del todo ausente de las preferencias de los lectores y las lectoras de este diario pero, como queda evidenciado en los titulares de las noticias más leídas, prefirieron aquellas noticias que informaban sobre aspectos más superficiales de la elección, como por ejemplo: "iLo mejor y lo peor! Así vistieron los diputados este 1 de mayo" (Agencia/Redacción, CRHoy.com, 01/05/17) o "La Dra. Virginia roba suspiros en el Congreso" (Castro, CR.Hoy.com, 01/05/17) (nota sobre la compañera sentimental del diputado Otto Guevara).

Por "brecha de las noticias", Boczkowski $y$ Mitchelstein (2015) se refieren a las diferencias entre la oferta y el consumo de noticias específicamente sobre asuntos públicos. Sin embargo, las preferencias específicas para el $1^{\circ}$ de mayo, así como, las tendencias generales descritas para el mes de mayo de 2017, sugieren que existe una correspondencia entre lo que oferta el medio y lo que prefieren sus lectores y lectoras: ambos privilegian asuntos no públicos. Por tanto, en lo que respecta a CRHoy.com, podría problematizarse la noción misma de "brecha en las noticias" en el sentido en que esta sugiere una preferencia por distintos temas, la cual no es representativa de este medio.

\subsection{TENDENCIAS EN LA OFERTA INFORMATIVA DE NACION.COM}

La oferta de contenidos evidencia una distribución muy similar entre "Asuntos Públicos" con un 51,1\% y "Asuntos No Públicos" que alcanza un $48,9 \%$. En otras palabras, a diferencia de CRHoy.com, el diario Nacion.com privilegió ligeramente la oferta de asuntos públicos en su versión Web. El género que predomina en la oferta informativa es la noticia con un $84,7 \%$. El predominio de la noticia sugiere una cobertura episódica de los acontecimientos, es decir, se abordan temas de manera superficial y bajo el criterio periodístico de la inmediatez. Asimismo, el bajo porcentaje de reportajes sugiere una escasa cobertura temática, es decir, la cobertura adolece de profundidad y de análisis coyuntural.

En el gráfico 3 puede verse que la agenda temática del medio se articula a partir de 9 temas recurrentes: deportes $(18,2 \%)$, política $(14,1 \%)$, economía $(12,6 \%)$, sucesos $(12,5 \%)$, asuntos internacionales $(7,5 \%)$, infraestructura y transportes $(7,8 \%)$, asuntos sociales $(9,5 \%)$, entretenimiento $(8,4 \%)$ ciencia y ambiente $(4,1 \%)$, turismo $(0,6 \%)$. Tres temas aparecen de manera tangencial: historias de éxito $(0,9 \%)$, otros $(1,6 \%)$ y curiosidades $(1,9 \%)$. El porcentaje de noticias sobre deportes es llamativo si se toma en cuenta que la versión impresa del sitio Web, La Nación, ha seguido históricamente una línea editorial de tendencia liberal y conservadora marcada por una defensa fuerte de las políticas neoliberales y de los intereses de las élites económicas del país (Robles $y$ Voorend, 2012). 


\author{
GRÁFICO 3 \\ AGENDA INFORMATIVA DEL MEDIO NACION.COM \\ MAYO, 2017
}

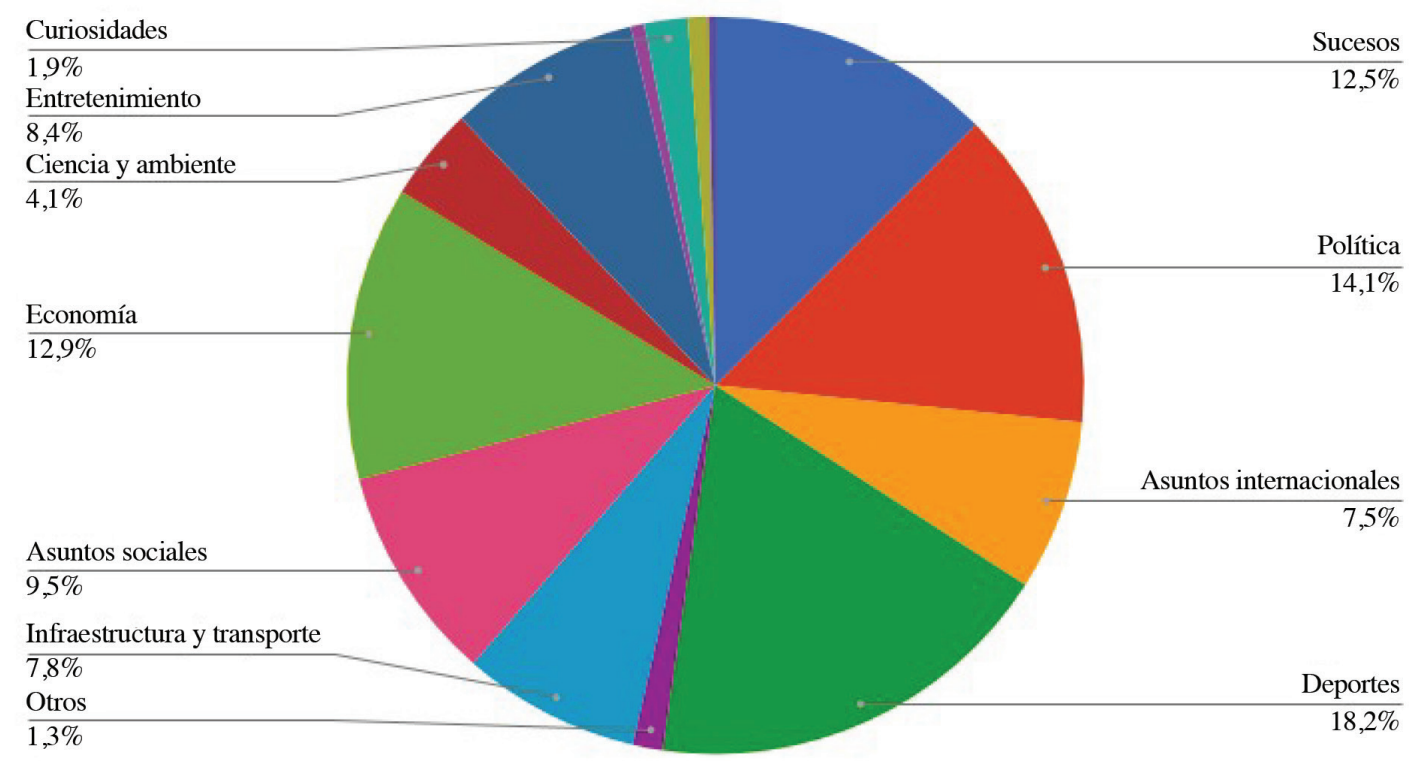

Fuente: Elaboración propia a partir de los datos de Nacion.com recolectados durante mayo de 2017.

Durante el $1^{\circ}$ de mayo, la noticia más importante, según los criterios del medio, fue "Nueve votos de fracciones quebradas se cotizan alto para definir la presidencia del Congreso" (Mata, Nacion.com, 01/05/17). Esta noticia corresponde a un tema de interés público, pero no deja de ser llamativo la construcción discursiva del titular, pues mediante la frase "se cotizan alto", se establece una analogía entre el congreso y un mercado bursátil, lo cual acaba desvirtuando el ejercicio legislativo en la medida que lo reduce al orden de la puja y la especulación, como sucede con las acciones de un mercado cambiario. A través de esta estrategia discursiva se obvian las tensiones $y$ negociaciones fallidas que tuvieron lugar ese día. Es importante recalcar que, aunque el contenido de la noticia sí llega a referir al proceso de negociación política, el efecto cognitivo del encabezado en términos de formación de opinión pública es superior al del contenido de la nota, pues el titular es lo que con mayor seguridad recordarán los lectores y las lectoras (van Dijk, 2009).

\subsection{TENDENCIAS EN LA DEMANDA DE NOTICIAS EN NACION.COM}

El $72 \%$ de las noticias más leídas en el sitio web de Nacion.com son de "Asuntos No Públicos", mientras que el $28 \%$ de las noticias más consultadas corresponden a contenidos sobre "Asuntos Públicos". En otras palabras, la diferencia entre la oferta y el consumo de noticias sobre asuntos públicos - la "brecha" en el sentido que le dan Boczkowski y Mitchelstein (2015) — es de 27,1\%. Este dato es importante por su similitud con su equivalente de CRHoy. com $(27,7 \%)$. En conjunto, estas cifras podrían sugerir que la falta de interés en asuntos públicos en Costa Rica es más estructural que episódica.

Como puede verse en el gráfico 4, la distribución de los temas más consultados por 
las lectoras y los lectores de Nacion.com, en orden descendente, fueron: deportes (30\%), entretenimiento $(21,2 \%)$, sucesos $(20,5 \%)$, asuntos sociales $(8,6 \%)$, economía $(5,8 \%)$, política (5,4\%), infraestructura $y$ transporte $(5,1 \%)$, asuntos internacionales (2\%) y ciencia y ambiente (1,4\%).

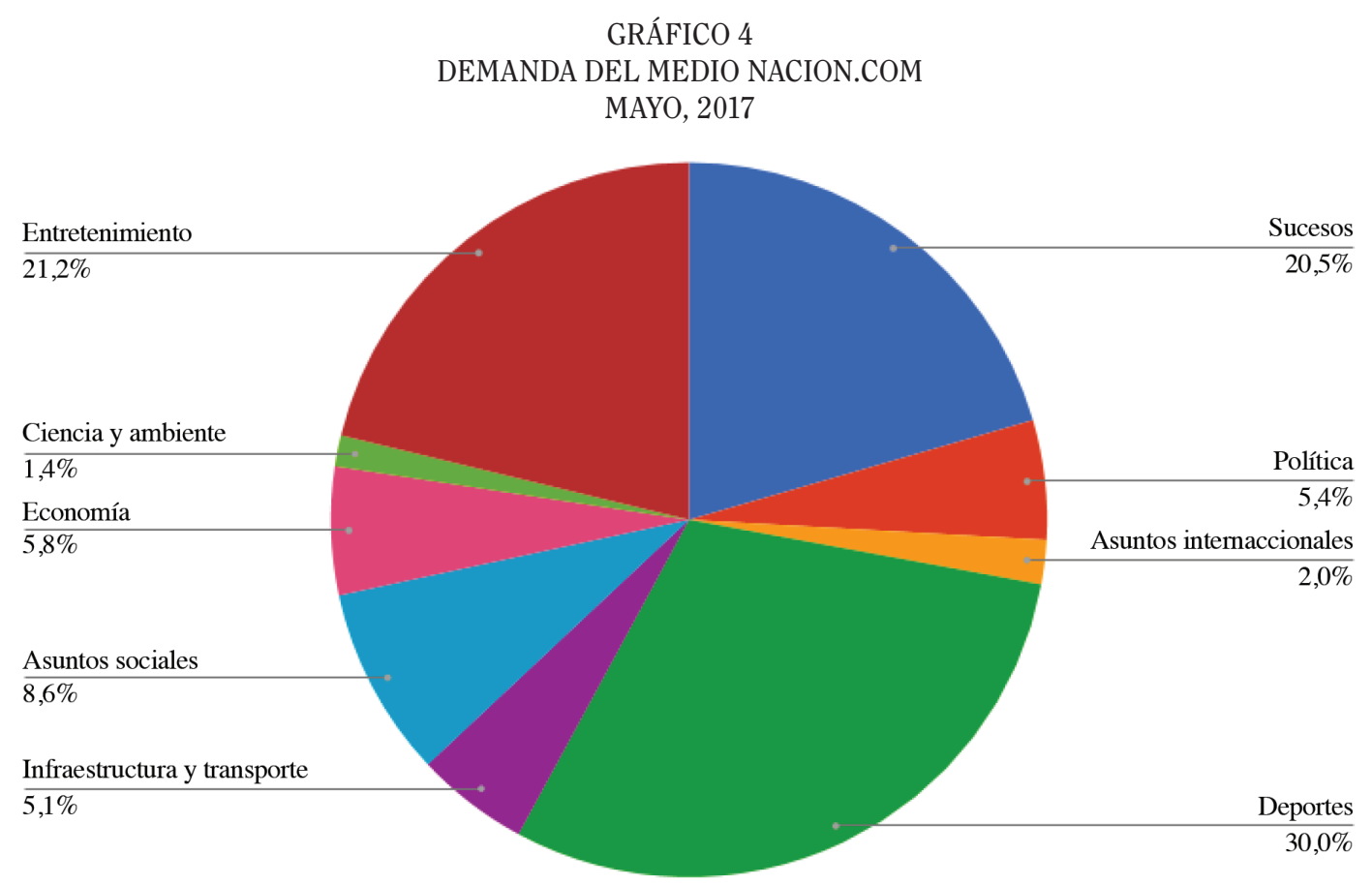

Fuente: Elaboración propia a partir de los datos de Nacion.com recolectados durante mayo de 2017.

En lo que respecta al caso concreto del $1^{\circ}$ de mayo, la noticia más leída se titulaba "Hospital de Niños advierte sobre riesgo de usar sujetadores de cabeza en sillas para niños" (Recio, Nacion.com, 01/05/17). En segundo y tercer lugar de preferencia se ubicó una noticia sobre los acontecimientos en la Asamblea, pero una vez más, desde la óptica de lo banal como demuestra el titular "Traje blanco y chancletas rompieron el protocolo el 1 de mayo" (Rodríguez, Nacion.com, 01/05/17).

Como puede observarse, en el caso de Nacion.com se detectó una oferta mayor de temas relacionados con asuntos públicos pero la diferencia porcentual entre estos y los contenidos que no son de interés público, es de apenas 2,2\%. Por tanto, a pesar de que el medio continúa articulando una agenda temática a partir de estos temas, es claro que acude a la estrategia de incluir otros que presenta bajo la forma de soft news, probablemente con el propósito de hacer frente a las presiones del medio digital. Un ejemplo de esta observación es la importancia que el diario le da a las noticias sobre deportes, las cuales constituyen el 18,2\% de la oferta, por encima de temas de política y economía que corresponden al 13,5\% y al $12,6 \%$, respectivamente.

\section{DISCUSIÓN}

En esta sección se desarrolla una síntesis comparativa entre cada medio a partir de las ocho variables de análisis. En primer término, la variable de fecha y hora de publicación evidencia que CRHoy.com actualiza sus contenidos con mayor frecuencia que Nacion.com. La lectura de las noticias evidencia que ello va 
en detrimento de la calidad de la información, pues las noticias de CRHoy.com suelen adolecer de profundidad e incluso, evidencian errores de ortografía y redacción.

El estudio de los formatos refleja una llamativa contradicción, pues CRHoy.com a pesar de ser un medio estrictamente digital, se limita al uso de texto e imagen. Esto contrasta con el sitio de Nacion.com, pues aunque es la versión digital de un diario tradicional, tiende a incluir más recursos modales (video y audio), aplicaciones $y$ formatos transmedia al presentar la información. Lo más llamativo de esta comparación es que CRHoy.com, a pesar de usar formatos más rudimentarios, supera en tráfico a Nacion. com. De acuerdo al sitio Alexa.com, CRHoy. com es el tercer sitio más visitado en Costa Rica, mientras que Nacion.com ocupa el decimoquinto lugar a nivel nacional. Lo anterior guarda relación con una tendencia que ya había sido identificada por Boczkowski y Mitchelstein (2015), quienes argumentan que los "formatos novedosos o nacidos en la web" no son necesariamente los más populares ni tampoco reciben más atención que los formatos tradicionales.

El análisis detallado de la variable del contenido sugiere que, en sus versiones Web, los medios de comunicación estudiados distribuyen su agenda entre temas de interés público $y$ aquellos que no lo son, como por ejemplo, los deportes, los sucesos y el entretenimiento. En el caso de Nacion.com, esta tensión entre lo público y lo no público se expresa en que, si bien se ofrecen ligeramente más asuntos públicos, la categoría individual que más se promueve es la referente a deportes. Asimismo, el análisis del discurso permitió identificar que el tratamiento que hacen los medios de los asuntos públicos se caracteriza por un encuadre que reproduce el llamado "infoentretenimiento". De acuerdo con Rius (2016), esta tendencia, aunada a la velocidad y la actualización constante, favorece la simplificación de los contenidos por parte de los $y$ las periodistas.

La tendencia hacia la simplificación se ve reforzada por el uso preponderante que ambos medios hacen del género de la noticia, lo cual a su vez, va en detrimento de otros géneros más complejos como los reportajes. La teoría indica que cada uno de esos géneros se construye a partir de dos tipos de meta-encuadres: para la noticia se emplea el encuadre episódico, mientras que para el reportaje se usa el encuadre temático. El primero se distingue porque describe principalmente episodios, mientras que el segundo retoma el contexto social y político de los acontecimientos (Sádaba, 2001). Por tanto, el encuadre episódico, al prescindir de los antecedentes $y$ los factores sociopolíticos que dan lugar al evento narrado, favorece la descontextualización y el desconocimiento de los procesos que causan un evento particular. Por su parte, el encuadre temático suele ser más profundo porque aporta explicaciones sobre el contexto de los acontecimientos que se están informando (Iyengar, 1990). Lo anterior indica que aunque se privilegien los temas sobre asuntos públicos, como es el caso de Nacion. com, el uso excesivo del género noticioso limita las posibilidades de comprender las causas y las consecuencias de los eventos relevantes para la realidad nacional.

Finalmente, las variables de autoría y fuente reflejan las diferencias en materia de las rutinas de producción al interno de cada diario. Por ejemplo, Nacion.com designa a un o una periodista la cobertura de un tema particular, lo cual evidencia que el medio implementa la especialización. Asimismo, el medio identifica de forma clara cuando la noticias proviene de una agencia internacional. En el caso contrario de CRHoy.com, se detectó que el mismo periodista cubre diversos temas y no siempre se da crédito a la fuente cuando se trata de una noticia de agencia. Lo anterior sugiere que ambos medios manejan distintos criterios sobre la calidad periodística, aunque no demasiado pues la cobertura que llevaron a cabo del $1^{\circ}$ de mayo evidencia más similitudes que diferencias entre los medios e incluso, las audiencias.

Tal y como se mencionó al inicio, el $1^{\circ}$ de mayo es una fecha de trascendencia histórica en el país; este año adquirió un matiz particular a raíz del carácter heterodoxo de la elección del directorio de la Asamblea Legislativa. No obstante, el análisis de contenido sugiere que, a pesar del valor noticioso de esta coyuntura, los medios estudiados no lo consideran un tema 
de importancia excepcional y lo mismo ocurre con los lectores y las lectoras que, aún en el marco de esta coyuntura, prefieren leer temas relacionados con deportes o el entretenimiento, $y$ que cuando deciden informarse sobre lo que sucedió en la Asamblea Legislativa, eligieron las notas sobre la indumentaria de los parlamentarios y parlamentarias, $y$ su grado de apego al protocolo que se estipula para esa fecha. La indiferencia mostrada ante el hito informativo del $1^{\circ}$ de mayo sugiere que los medios no asumieron una posición de periodismo vigilante y que las personas lectoras tampoco ejercieron el rol de "ciudadanía de monitoreo" en el sentido propuesto por Boczkowski y Mitchelstein (2015).

\section{CONSIDERACIONES FINALES}

El presente estudio se articula a partir de dos interrogantes específicas: ¿cuáles temas caracterizan la oferta informativa de dos medios digitales, Nacion.com y CRhoy.com? y ¿qué tipos de noticias consumen los lectores y las lectoras de los diarios analizados? A partir de los resultados es posible afirmar que Nacion. com tiende a ofrecer un mayor porcentaje de noticias sobre asuntos públicos (política, economía, educación), mientras que CRhoy.com difunde un porcentaje ligeramente mayor de noticias sobre asuntos que no son de interés público (deportes, sucesos y entretenimiento). Las personas que consultan estos medios prefieren, en ambos casos, consumir noticias sobre asuntos que no son de índole público.

Los resultados sugieren la existencia de una brecha de las noticias, ya que las personas prefieren los asuntos no públicos, a pesar de que los medios les ofrecen más noticias sobre asuntos de carácter público. En función de lo anterior, se afirma que la brecha opera como algo más estructural que episódico, es decir, se mantiene salvo en aquellos momentos o episodios excepcionales de la vida democrática. Podría decirse que esto no es nuevo, ni causa mayor sorpresa pues es un fenómeno que ha sido registrado también en otros contextos, se considera que lo realmente relevante de estos datos es su potencial a futuro en el tanto que permitirán explorar si la brecha noticiosa se revierte en periodos de actividad política intensificada, como las elecciones nacionales. Es por ello, que los hallazgos puntualizados en este artículo constituyen un referente para identificar si, en épocas de actividad política intensa, los medios y la ciudadanía adoptan posturas de mayor monitoreo sobre los asuntos de interés público.

En esa misma línea, los resultados invitan a matizar el concepto de "brecha de las noticias". Ese concepto sugiere la existencia de cierta divergencia en el tanto que los medios de comunicación y sus audiencias apuestan por cosas distintas: los primeros aspiran a ofrecer contenidos públicos, mientras que las segundas optan por consumir noticias sobre asuntos no públicos. Sin embargo, la evidencia presentada en este artículo dista parcialmente de ese escenario, pues ambos medios analizados ofrecen contenidos sobre asuntos no públicos y asuntos públicos en proporciones muy similares, en otras palabras, hasta qué punto se puede hablar de la existencia de una "brecha" cuando el porcentaje de las noticias que ofrecen los medios sobre asuntos públicos es ligeramente mayor que las noticias sobre asuntos no públicos, ante este escenario, se proponen dos nuevas formas de mirar la brecha de las noticias.

En primer lugar, se sugiere que en lugar de enfocarse en la "brecha" de interés por noticias de asuntos públicos, se considerara un "índice de similitud" en el interés por noticias sobre asuntos no públicos (calculado al restar la oferta a la demanda de noticias sobre estos temas). De hecho, si se aplicase a los casos analizados, tanto CRhoy.com como Nacion. com mostrarían números altos: $38,1 \%$ y 23,1\%, respectivamente. Este ejercicio sugeriría que las noticias sobre asuntos no públicos tienen una demanda insatisfecha, por tanto, una línea de investigación futura podría confirmar si, a largo plazo, los medios de comunicación están cediendo a este deseo al aumentar el "índice de similitud" (entre lo que ofrecen y lo que realmente desean leer las audiencias) y desvirtuar la llamada "brecha de las noticias".

En segundo lugar, otra forma de problematizar la brecha de las noticias vendría en conjunción con lo argumentado por el artículo de Carazo (en este número), para quién la brecha de las noticias coexiste con cierto 
grado de interés por parte de la ciudadanía por asuntos públicos, lo cual se vería evidenciado en su anuencia por participar de la política en el mundo digital. En función de lo anterior, se considera que la investigación sobre este tema no va en la línea de privilegiar un fenómeno sobre otro, sino en asumir que ambos - la brecha noticiosa y el interés por los asuntos públicos- coexisten $y$ deben ser analizados en todas sus formas de expresión. Lo anterior obliga a expandir el objeto de estudio más allá de los medios tradicionales o las redes sociales e incluso, cuestionar la distinción entre asuntos públicos y no públicos, tal y como se plantea en el artículo de Siles, Campos y Segura (en este número).

En un sentido más amplio, los hallazgos invitan a pensar la dimensión política del consumo mediático. Las personas, a la hora de decidir qué temas consumir online, asumen una posición política, ya sea por activa o por pasiva, al elegir conscientemente una noticia de entretenimiento por encima de otra sobre economía o por el contrario, al ignorar del todo las noticias sobre política nacional. El carácter cotidiano de las elecciones que orientan el consumo mediático puede llegar a desvirtuar la importancia cívica que revisten. No obstante, no debe perderse de vista su peso e importancia para el estudio de otras variables democráticas como lo son las actitudes y el conocimiento político.

A pesar de la importante relación que existe entre consumo mediático y el ejercicio de la ciudadanía, las ciencias políticas han tendido a ignorar el peso de los medios en sus análisis. Por tanto, los resultados presentados en este artículo son, a su vez, una invitación a establecer "zonas de contacto" (Sandoval, 2009) entre las ciencias políticas y los estudios en comunicación, con el fin de articular las respuestas que el sistema democrático y la ciudadanía costarricense tanto necesitan.

\section{REFERENCIAS}

Agencia/Redacción. (01/05/17). ;Lo mejor y lo peor! Así vistieron los diputados este 10 de mayo. CRhoy.com. Recuperado de https://www.crhoy.com/entretenimiento/ lo-mejor-y-lo-peor-asi-vistieron-los-diputados-este-1-de-mayo/

Althaus, S. (2003). Collective Preferences in Democratic Politics. Cambridge: Cambridge University Press.

Berrocal Gonzalo, S., Redondo García, M., y Campos Domínguez, E. (2012). Una aproximación al estudio del infoentretenimiento en Internet: origen, desarrollo y perspectivas futuras. Adc, (4), 63-79. doi:10.6035/2174-0992.2012.4.5

Boczkowski, P. y Mitchelstein, E. (2015). La brecha de las noticias. La divergencia entre las preferencias informativas de los medios y el público. Buenos Aires: Manantial.

Brussino, S., Rabbia, H.H., y Sorribas, P. (2009). Perfiles Sociocognitivos de la Participación Política de los Jóvenes. Revista Interamericana de Psicología, 43 (2), 279-287.

Casals-Carro, M. (2005). Periodismo y sentido de la realidad. Madrid: Editorial Fragua.

Castro, K. (01/05/2017). La Dra. Virginia roba suspiros en el Congreso. CRhoy.com. Recuperado de https://www.crhoy.com/ entretenimiento/la-dra-virginia-robasuspiros-en-el-congreso/

Castro, K. (01/05/2017). Mayoría de diputados se apegó al protocolo. CRhoy.com. Recuperado de https://www.crhoy.com/ nacionales/mayoria-de-diputados-se-apego-al-protocolo/

Chalaby, J. (1998). The invention of journalism. Hampshire: Macmillan Press.

CRHoy.com.(2018). Mediakit publicitario: abril 2018. Recuperado de http://pull.crhoy. net/crhoy.com-mediakit.pdf

DelliCarpini, M.X., y Keeter, S. (1996). What Americans Know About Politics and Why It Matters. New Haven: Yale University Press.

Fairclough, N. (1995). Media Discourse. London: Edward Arnold.

Ferrín, M. y Fraile, M. (2014). La medición del conocimiento político en España: problemas y consecuencias para el caso de las diferencias de género. Revista Española de Investigaciones Sociológicas, 147, 53-71. 
Glassner, B. (2009). The culture of fear. Why Americans are afraid of the wrong things? New York: Basic Books.

Gomis, L., y Giner, S. (2008). Teoría de los géneros periodísticos. Barcelona: uocpress.

Greer, C. (2010). Crime and media. London: Routledge.

Grupo Nación. (2018). Audiencias. Recuperado de http:/gncpassword.com/downloads/ otros/press-audiencias-gnc-cifras-marzo-2018

Habermas, J. (1989). Teoría de la acción comunicativa. Madrid: Taurus.

Imbert, G. (2003). El zoo visual. De la televisión espectacular a la televisión especular. Barcelona: Gedisa.

Iyengar, S. (1990). Framing responsibility for political issues: The case of poverty. Political Behavior, 12(1), 19-40. http:// dx.doi.org/10.1007/bf00992330

Kim, Y., Chen, H. y Gil de Zúñiga, H. (2013). Stumbling upon news on the Internet: Effects of incidental news exposure and relative entertainment use on political engagement. Computers in Human Behavior 29, 2607-2614.

Krippendorff, K. (2004). Reliability in Content Analysis. Human Communication Research, 30 (3), 411-433. doi: 10.1111/ j.1468-2958.2004.tb00738.x

Mata, E. (01/05/2017). Nueve votos de fracciones quebradas se cotizan alto para definir la presidencia del Congreso. Nacion.com. Recuperado de http://www. nacion.com/nacional/politica/Diputadosarrancan-acuerdos-presidenteCongreso_0_1631036916.html

Mendoza, A. (01/05/2017). Doña Merry, Paquito $y$ la giganta tiñeron de colores la Avenida Segunda. CRhoy.com. Recuperado de https://www.crhoy.com/nacionales/donamerry-paquito-y-la-giganta-tineron-decolores-la-avenida-segunda/

Mondak, J.J y Anderson, R. (2004). The Knowledge Gap: A Reexamination of Gender-BasedDifferences in Political Knowledge. The Journal of Politics, 6(62), 492-512.
Morris, J. (2005). The Fox News Factor. Harvard International. Journal of Press/Politics, 10(3), 56-79. doi: 10.1177/1081180X05279264

Moy, P., Xenos, M., y Hess, V. (2005). Communication and Citizenship: Mapping the Political Effects of Infotainment. Mass Communication and Society, 8(2), 111-131. http://dx.doi. org/10.1207/s15327825mcs0802_3

Prior, M. (2007). Post-Broadcast Democracy. How Media Choice Increases Inequality in Political Involvement and Polarizes Elections. Cambridge, New York: Cambridge University Press.

Programa de la Sociedad de la Información y el Conocimiento (PRosic). (2016). Informes hacia la sociedad de la información y el conocimiento, 10. Recuperado de http:// www.prosic.ucr.ac.cr/informe-2016.

Ramírez, A. (01/05/2017). Diputado Juan Marín: "Nadie está alcanzando los 29 votos". CRhoy.com. Recuperado de https://www. crhoy.com/nacionales/diputado-juanmarin-nadie-esta-alcanzando-los-29-votos/

Recio, P. (01/05/2017). Hospital de Niños advierte sobre riesgo de usar sujetadores de cabeza en sillas para niños. Nacion.com. Recuperado de http://www. nacion.com/nacional/salud-publica/ Hospital-Ninos-advierte-sujetadorescabeza_0_1630436964.html

Rius, J, (2016). Periodismo en Reconstrucción: de la crisis de la prensa al reto de un oficio más independiente y libre. Barcelona: Publicacions i Edicions de la Universitat de Barcelona.

Robles, F. y Voorend, K. (2011). Los dueños de la palabra en Costa Rica en un contexto de reforma neoliberal. Rupturas 1(2).

Rodríguez, I. (01/05/17). Traje blanco y chancletas rompieron el protocolo este $1 .^{\circ}$ de mayo. Nacion.com Recuperado de https://www.nacion.com/el-pais/politi$\mathrm{ca} /$ traje-blanco-y-chancletas-rompieron-el-protocolo-este-1-deg-de-mayo/ D36PL2WJGZCYRGPSZ6OIMCNFE4/ story/ 
Sádaba, M. T. (2001). Origen, aplicación y límites de la «teoría del encuadre» (Framing) en comunicación. Comunicación y Sociedad, 14, 2, 143-175.

Sandoval, C. (2009). Zonas de contacto en las ciencias sociales. In E. Cook, Género y religión. Sospechas y aportes para la reflexión. San José: Universidad Bíblica Latinoamericana.

Siles, I. y Boczkowski, P.J. (2012). Making sense of the newspaper crisis: A critical assessment of existing research and an agenda for future work. New Media \& Society, 14(8), 1375-394. doi: $10.1177 / 1461444812455148$

Solano, H. (01/05/2017). Nuevo receso caldea los ánimos en el Plenario. CRhoy.com. Recuperado de https://www.crhoy.com/ nacionales/nuevo-receso-caldea-los-animos-en-el-plenario/

Tsfati, Y. y Cappella, J. (2003). Do People Watch what they Do Not Trust? Communication Research, 30(5), 504-529.

Ugarte, J. (01/05/2017). iSin humo blanco! Diputados tomarán cuarto receso.
CRhoy.com. Recuperado de https://www. crhoy.com/nacionales/sin-humo-blancodiputados-tomaran-cuarto-receso/

Ugarte, J. (01/05/2017). Gonzalo Ramírez suma votos y se acerca a presidir el congreso. CRhoy.com. Recuperado de https://www. crhoy.com/nacionales/gonzalo-ramirezsuma-votos-y-se-acerca-a-presidir-elcongreso/

van Dijk, T. (1990). La noticia como discurso. España: Paidós.

White, M. D., y Marsh, E. E. (2006). Content analysis: A flexible methodology. Library Trends, 55(1), 22-45. doi: 10.1353/ lib.2006.0053

Xiang, Y. y Sarvary, M. (2007). News Consumption and Media Bias. Marketing Science 26 (5), 611-628. doi: 10.1287/ mksc. 1070.0279

Fecha de ingreso: 24/10/2017 Fecha de aprobación: 15/03/2018 